\title{
Morphological Evolution of Thick Wax Deposits during Aging
}

\author{
Probjot Singh, Ramachandran Venkatesan, and H. Scott Fogler \\ Dept. of Chemical Engineering, University of Michigan, Ann Arbor, MI 48109 \\ N. R. Nagarajan \\ Mobil Technology Company, Dallas, TX 75244
}

\begin{abstract}
The presence of waxes in crude oil can lead to the formation of wax deposits on the walls of cold subsea pipelines, which restricts flow and can lead to plugging of the pipelines. This problem has recently become more significant as the production wells move further offshore causing the oil to be cooled below the cloud point before reaching shore. Wax deposition was studied in the laboratory under conditions simulating the deposition in a subsea pipeline. Wax deposition is initiated by the precipitation of wax directly on the pipe wall and the formation of a network of wax crystals (wax-oil gel) with significant amounts of oil trapped in it. Radial diffusion of the wax molecules from the bulk solution to the gel deposit causes it to simultaneously grow and age with time. The wax molecules diffusing into the gel deposit precipitate near the interface resulting in a faster aging rate of the deposit near the interface than that near the wall. This nonuniform aging of the wax deposit causes the evolution of complex morphologies of the wax deposits. The diffusion of wax molecules into the gel matrix was analyzed theoretically during the growth of the wax deposit. This mathematical model predicted the radial variation of the morphology of the wax deposit observed in the laboratory flow loop experiments along with the deposit thickness as a function of time.
\end{abstract}

\section{Introduction}

Solid deposition phenomena occur during various chemical operations in many systems such as crystallization fouling of heat exchangers (Bott, 1997), frost formation on cold surfaces (Lee et al., 1997) and scale deposition in porous media (El-Hattab, 1985). The deposition of crystals on heat exchanger surfaces is common in aqueous systems. When the cold surface of a heat exchanger is exposed to warm, moist air, a layer of frost deposits, resulting in decreased efficiency of the heat exchanger in the refrigeration unit. In petroleum production, transportation and processing, deposition of organic material (such as paraffin wax) in the flow lines reduce the flow capacity of the flow line. The formation of the paraffin deposits, at the pipe-walls, plugs the pipeline and restricts the flow (Figure 1). This problem has recently become more significant as the production wells move further offshore causing the oil to be cooled below the cloud point before

Correspondence concerning this article should be addressed to H. S. Fogler. reaching shore. If mechanical techniques, such as pigging, are to be used to prevent wax buildup, an understanding of the rate of formation and the properties of the deposits is necessary. In a previous article (Singh et al., 2000), the growth and aging of thin film incipient gels were elucidated. The objective of this work is to elucidate the morphological and compositional changes (aging) in the thick wax deposits that form during the flow of waxy crude oils through cold pipelines.

Thick deposits of wax-oil gels can be formed from crude oil when the oil is exposed to cold temperatures. Crude oil is a complex mixture of hydrocarbons consisting of paraffins, aromatics, naphthenes, resins and asphaltenes. Among these groups of hydrocarbons, high molecular weight paraffins (waxes) are responsible for some of the problems that are encountered during transportation and processing of the crude oil. The high molecular weight paraffins have a low solubility in most of the aromatic, naphthenic, and other organic solvents at room temperatures. At offshore reservoir 


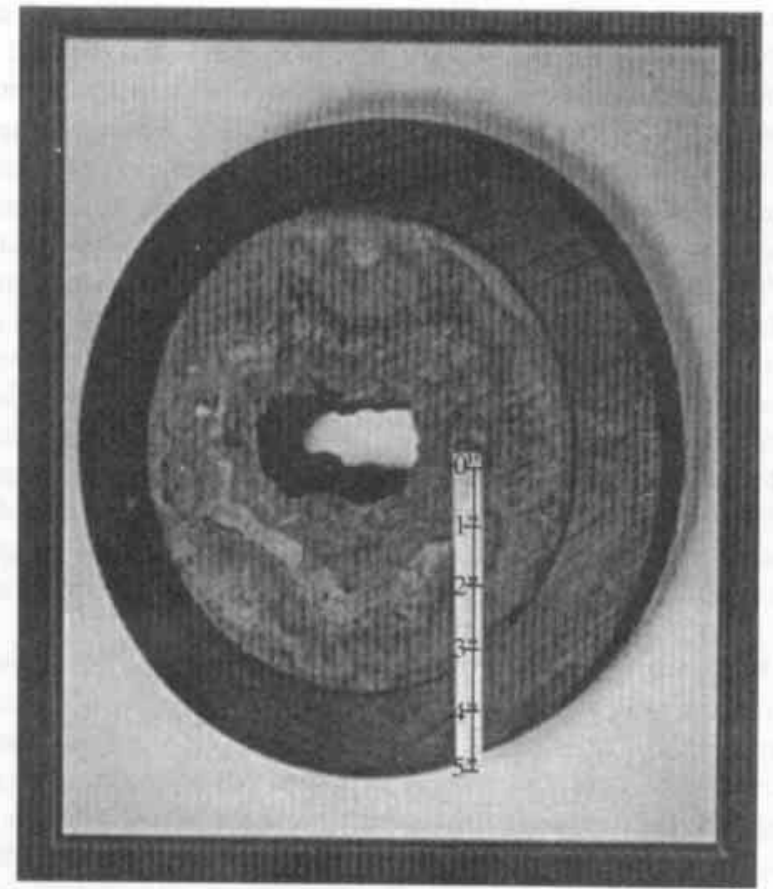

Figure 1. Cross-sectional view of a plugged pipeline in a Gulf of Mexico field.

temperatures $\left(70-150^{\circ} \mathrm{C}\right)$ and pressures $(8,000-15,000 \mathrm{psi}$, 55-103 MPa), the solubility of these compounds is sufficiently high to keep them fully dissolved in the mixture and the crude oil behaves as a Newtonian fluid with a low viscosity. Once the crude oil leaves the reservoir and flows through the tubing and subsea pipelines, its temperature begins to drop due to the cooler environment.

The fact that the solubility of high molecular weight paraffins decreases drastically with decreasing temperatures leads to the formation of stable wax crystals at low temperatures. This crystallization of paraffins results in the formation of wax-oil gels with a complex morphology (Figure 2). The waxoil gelation is due to the flocculation of orthorhombic wax crystallites that appear in the solution during cooling (Dirand et al., 1998). Observations with a cross-polarized microscope revealed that the crystallites have structures of platelets that overlap and interlock (Holder and Winkler, 1965a). It was previously thought that the deposits, similar to those shown in Figure 1, were solely composed of paraffin wax. However, a gel deposit with as little as $2 \%$ wax was obtained from our laboratory flow experiments. Other studies on distillate fuels also show that as little as $2 \%$ of the precipitated wax is sufficient to gel the distillate fluid (Holder and Winkler, 1965b). The composition of the gel as well as the rate of gelation depends on the conditions at which the gel is deposited. As the wax-oil mixture is cooled below the cloud point, a gel is formed and the nature of this gel depends strongly on the cooling rate (Singh et al., 1999).

A number of mechanisms have been proposed to elucidate wax deposition on pipe walls. These mechanisms include molecular diffusion, shear dispersion, Brownian diffusion, and gravity settling (Bern et al., 1980; Burger et al., 1981; Majeed et al., 1990). Wax particles start appearing in the crude oil

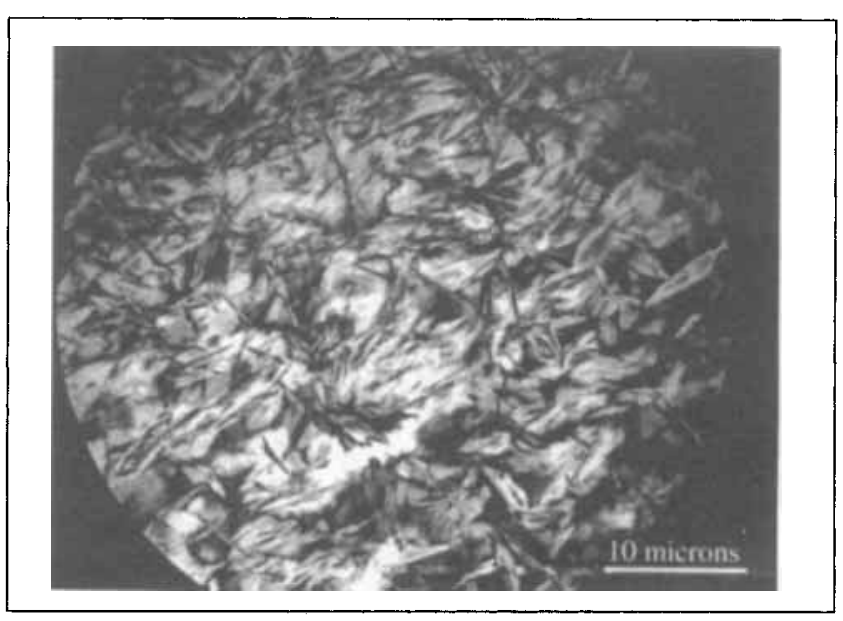

Figure 2. Microscopic image of the incipient gel layer deposit in a flow cell under a laminar flow.

when the bulk temperature drops below its cloud point (solubility limit). The deposition of the wax in the particulate state is determined by mechanisms such as shear dispersion, Brownian diffusion, and gravity settling. Our experimental results, however, confirm that particulate deposition is not significant for flow conditions encountered in oil pipelines on the ocean floor (Singh et al., 2000). Hence, gelation, along with the molecular diffusion mechanism, is the focus of studies.

A number of mathematical models have also been developed that describe the deposition process. All of the models are based on the premise that wax-oil deposits have a constant wax content (Brown et al., 1993; Bern et al., 1980; Burger et al., 1981; Majeed et al., 1990; Svendsen, 1993; Ribeiro et al., 1997). The composition of the gel, as well as the rate of gelation, depends on the conditions at which the gel is deposited. The wax-oil mixture gels with cooling, and the nature of this gel depends strongly on the cooling rate (Singh et al., 1999). In all existing models, the oil content of the deposit is used as an adjustable parameter to match results from flow loop experiments with model predictions. These models only predict the time trajectory of the deposit thickness and do not take into account the variation of deposit composition with time. Although the experimental data for the deposit thickness is well matched with the model predictions by an arbitrary value of this adjustable parameter, these models cannot predict the deposit composition as a function of time and axial location. The assumption that the composition of the deposit is time invariant is found to be invalid in our laboratory flow loop experiments. Inasmuch as these models assume a constant value for the oil content, they are not accurate and cannot be applied to predict the thickness profile and the nature and properties of the wax deposit (such as hardness, melting point, and heat of fusion) which can vary significantly with time. Selection of the technique to remove the deposits in the pipeline depends on the nature of the deposit and hence, the prediction of properties of the wax deposits is essential. One such technique to remove the wax deposits has been described by Singh and Fogler (1998).

The incipient wax-oil gel deposit contains a significant amount of oil trapped in a 3-D network structure of the wax 


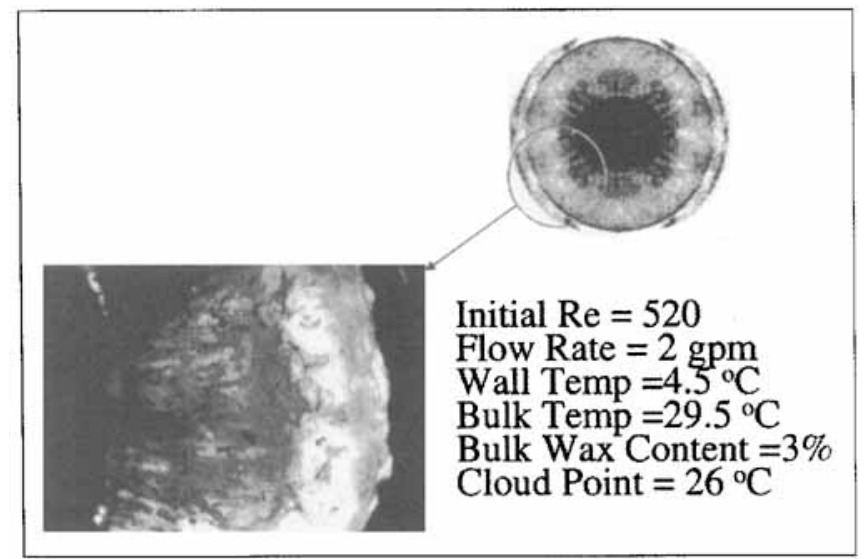

Figure 3. Thick gel deposit in the flowloop showing radial variation in the composition.

crystals (Singh et al., 2000). Hence, the gel behaves as a porous medium in which wax molecules continue to diffuse due to the radial variation in temperature and wax concentration. Thus, the wax content of the deposited gel increases with time. This process is called aging of the gel deposit. A mathematical model was developed to predict the growth and aging of the incipient thin gel deposits (Singh et al., 2000). This model was based on the assumption that the properties of the deposit are radially invariant. While this assumption is valid for the thin incipient gels, it is not valid for the thick gel deposits obtained in our laboratory flow loop experiments (Figure 3). Consequently this model is applicable only for the thin-film gel deposits and cannot be used to predict the properties of a thick gel deposit. The wax molecules diffusing into the thick gel deposit precipitate near the interface, which results in the faster aging rate of the deposit near the interface than that near the wall (Figure 3 ). This nonuniform aging of the deposit leads to the radial variation in the composition and morphology of the wax deposit.

To elucidate the evolution of the radial morphologies of the wax deposits, a model wax-oil system was studied in the laboratory. This model wax-oil system was prepared by dissolving a sample of food grade wax (Mobil M140) into an oil solvent (a 3:1 mixture of mineral oil and kerosene). A laboratory flow loop was used to perform the wax deposition experiments. Thick gel deposits were radially divided into two layers and analyzed for the compositional variation using Differential Scanning Calorimeter (DSC). It was found that the layer near the solid-liquid interface had higher wax content and faster aging rate than the layer close to the pipe wall. Based on this physical model of the wax deposition, a mathematical model was developed to simulate the variation of the thickness and the radial composition of the deposit with time. A system of coupled partial differential and algebraic equations generated from heat and mass balances inside the gel deposit was added to the previous thin film model (Singh et al., 2000). The theoretical model predictions are compared with the experimental results.

\section{Physics of Wax Deposition}

The solubility of a solute in a solvent is a strong function of temperature as observed in almost all examples of deposition discussed previously. Changes in the temperature may supersaturate the system, which results in precipitation of the solute directly on the surface and formation of a deposit. A generalized step-by-step mechanism of the deposition process had been discussed (Singh et al., 2000). When a sample of waxy oil is cooled, it gels due to the formation of a network of wax crystals. Unlike the inorganic solutions, where there is virtually no interaction among salt crystals (Bott, 1997), the wax crystals have a strong physical interaction and affinity, resulting in the formation of a network. Although oil (solvent) and wax (solute) have a similar chemical nature, their molecular weights are quite different. Waxes have a higher molecular weight and tend to form stable wax crystals that interlock to form a solid network (Wardhaugh and Boger, 1991). The network of wax traps a large quantity of oil (Holder and Winkler, 1965a). Hence, the initial stage of the deposition of the waxy oil mixture on a cold surface is the formation of a gel layer with a large fraction of trapped oil.

Waxy oil refers to a mixture of hydrocarbons of varying carbon numbers. When this mixture is cooled to a certain temperature, a fraction of hydrocarbons with carbon numbers above a certain value precipitate out as stable crystals trapping the remaining hydrocarbons to form a gel (Singh et al., 2000). The formation of such gels on a cold surface is the first step of this deposition process. The trapped liquid acts as a medium for further diffusion of the molecules with carbon numbers above a certain value (the critical carbon number) into the gel. This diffusion of heavier molecules is accompanied by the counter-diffusion of the molecules with carbon numbers below the critical carbon number out of the deposit (Singh et al., 2000). This process leads to an increase in the fraction of molecules with carbon numbers greater than the critical carbon number and also to a decrease in the fraction of molecules with carbon number lower than the critical number, in the gel. A mixture of model wax and model oil was used in a flow-loop setup in the laboratory (Singh et al., 2000). The samples of the wax-oil gel deposit collected from the wall of the tubing at various times (Singh et al., 2000), were analyzed using HTGC. To determine the changes in the carbon number distributions of the gel deposits with time, the distribution of the oil sample was subtracted from those of the gel deposits (Figure 4). It was observed that the mass fractions of hydrocarbons having carbon number greater than 28 increase with time and mass fractions of those having carbon number less than 28 decrease with time. Figure 4 shows that the hydrocarbons having carbon number greater than 28 diffuse into the gel deposit and those having carbon number less than 28 diffuse out of the gel deposit. Thus, this aging process in the flow loop is a counter-diffusion phenomenon. At the given operating conditions, the critical carbon number is 28 (Singh et al., 2000).

The critical carbon number is a function of composition of the crude oil, as well as the operating conditions, such as wall temperature and would consequently be different for different waxy oils. The gels with higher wax content are normally harder and more difficult to mechanically break as compared to those with lesser wax content. Hence, the diffusion process hardens the deposited gel with time, making the wax removal process difficult.

The aging of thin gel films deposited on the pipe wall was a counter-diffusion process where heavier paraffin molecules diffuse into the gel film and lighter oil molecules diffuse out 


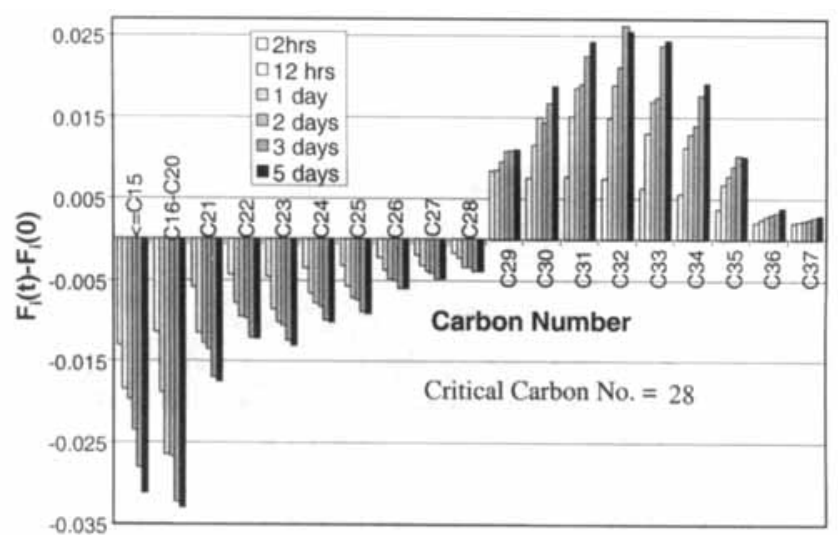

Figure 4. Changes in carbon number distribution of gel deposits from the flowloop with times.

of the gel film (Singh et al., 2000). The rate of molecular diffusion inside the gel was a strong function of the composition of the gel. Being a thin gel film, the variation of the composition along the thickness was significantly small and was assumed that the thin gel film had a uniform composition (Singh et al., 2000). For the thick gel deposits, however, the experiments showed that the composition varies significantly along the radial thickness, and hence the rate of diffusion of wax molecules into the gel is not uniform (Figure 3). This nonuniform rate of molecular diffusion leads to a nonuniform aging of the thick wax-oil gels. The following section describes this nonuniform aging process in detail.

\section{Morphology of the wax deposit}

The gel was also found to harden with time as a result of the increase in the wax content of gel. The fact that hardening (aging) of the deposit is not uniform in the radial direction leads to complex morphologies of the deposits. Flow-loop experiments were performed to observe the growth and aging of the gel deposit. A wax-oil mixture with $3 \mathrm{wt} . \%$ of wax entered the test section at a temperature of $29.5^{\circ} \mathrm{C}$, where the wall temperature of the tubing was maintained at $4.5^{\circ} \mathrm{C}$. Experiments for four different aging times of $12 \mathrm{~h}, 24 \mathrm{~h}, 48 \mathrm{~h}$ and $96 \mathrm{~h}$ were carried out at a content flow rate corresponding to a Reynolds number of $520\left(2.0 \mathrm{gal} / \mathrm{min}\right.$ or $1.26 \times 10^{-4}$ $\mathrm{m}^{3} / \mathrm{s}$ ). Samples of the wax-oil gel deposit were collected from the wall of the tubing after each experiment and were divided into two layers to observe the radial variation in the composition.

Different layers of the deposit were analyzed for the wax content using a differential scanning calorimeter. Figure 5 shows the trajectories of the internal radius (radius available for flow) and the wax content of the two layers of the deposit during a flow-loop experiment. It was observed that, while the growth of the thickness of the deposit virtually stops after $12 \mathrm{~h}$, the wax content of the deposit continues to increase. The deposited gel acts as an insulator to the radial heat transfer. As the deposit thickness grows, the insulating effect increases and the driving force for further deposition significantly diminishes. The wax content of the layer near the interface increases faster than that near the wall. The fact that

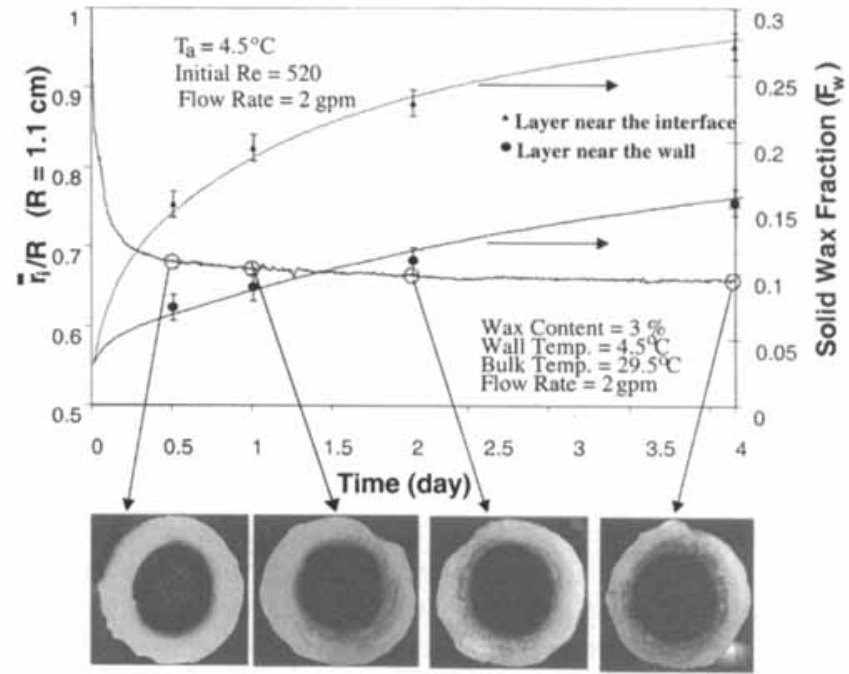

Figure 5. Thickness of the deposit and wax content trajectories of the two layers for a flow rate of 2 gpm $(R e=520)$.

the characteristic diffusion length of the wax molecules in the gel deposit is shorter than the deposit thickness causes this nonuniform aging of the gel deposit. Pictures of the deposits taken at various times also indicate the differences in the composition of these deposits (Figure 5).

\section{Model Development}

A model for the incipient thin-film gel deposits was previously developed (Singh et al., 2000). The thin-film model is based on the assumption that the composition of the wax deposit does not vary in the radial direction, while the assumption is valid for thin gels that cannot be used to predict the growth and composition of thick gel deposits. Consequently, a comprehensive model that accounts for the radial variation in the wax content of the deposit must be developed. The additional differential equations developed for the comprehensive model are described in the following sections.

\section{Assumptions of processes occurring within the wax layer}

The thin-film model does not describe the mechanisms by which wax molecules are distributed in the wax deposit during the aging process. To understand the mechanism by which every layer of the wax deposit ages with time, a "comprehensive model" of the wax deposition was developed. This section describes the microscopic phenomenon in the wax deposit.

The basic assumptions of the thick deposit model considered here are as follows:

1. The concentration of wax in the trapped oil at every point in the wax deposit is assumed to be the equilibrium wax content at the existing temperature.

2. Every layer of the wax deposit ages with time because of the molecular diffusion of wax inside the deposit. The wax concentration gradient, which is a result of the temperature gradient in the trapped oil phase, causes this transport of wax molecules through the trapped oil phase. 
3. The thermal conductivity of the wax layer can be represented as a function of the solid wax content of the wax layer.

4. Heat conduction in the wax deposit is one-dimensional.

5. The heat and mass transfer characteristics of the boundary layer control the wax deposition process on the oil side of the solid-liquid interface.

\section{Qualitative description to the model}

Qualitatively, this model is based on the same physical concepts as those used in the thin-film model. Some of the physical concepts, however, are extended to explain the microscopic occurrences in the wax deposit. It was assumed in the thin-film model (Singh et al., 2000) that wax molecules diffuse into the wax deposit as a result of the concentration gradient existing at the deposit surface. This model extends this physical idea to explain the processes occurring inside of the wax deposit. It assumes that at every layer in the wax deposit, the wax concentration in the trapped oil phase is in equilibrium with the wax crystals at the prevailing temperature. Consequently, a wax concentration gradient exists at every point in the trapped oil. During the aging process, each layer of the wax deposit ages under the prevailing equilibrium conditions.

The mathematical formulation of this model is obtained by writing the energy and material balances on differential elements of the wax layer. The solid-liquid interface conditions, which were the basis for the complete mathematical formulation of the "thin-film model," are taken as only one set of boundary conditions. The other set of boundary conditions is taken at the cold wall. This model describes the development of the wax fraction distribution within the wax deposit.

\section{Material balance inside the deposit}

The radial temperature gradient inside the porous wax deposit, where the wall temperature is lower than the cloud point temperature, gives rise to a radial gradient of wax concentration in the trapped oil, inasmuch as the wax concentration depends on the temperature. The wax concentration in the trapped oil at the interface is higher than that at the wall owing to the higher interfacial temperature. This concentration gradient leads to a radial diffusive flux of wax molecules toward the wall through the trapped oil medium. A material balance on a differential element (Figure 6) of the wax deposit can be written in terms of the weight fraction $F_{w}$, area $A$, and mass flux, $J$

$$
A \Delta r \rho_{\mathrm{gel}} \frac{\partial F_{w}(r, t)}{\partial t}=\left.(A J)\right|_{r}-\left.(A J)\right|_{r+\Delta r}
$$

The mass flux, $J$, by the concentration gradient can be written as

$$
J=-D_{e}(r) \frac{\partial C_{w s}}{\partial r}
$$

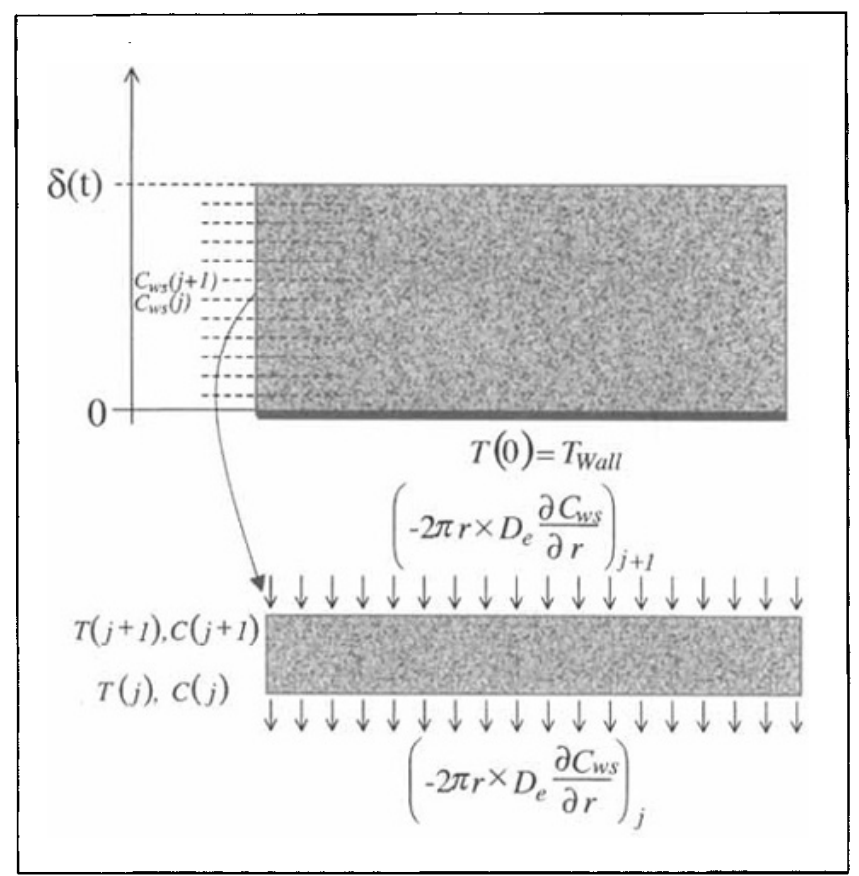

Figure 6. Gel deposit and the differential element.

and substituting Eq. 2 into Eq. 1, one obtains

$$
\rho_{\mathrm{gel}} \frac{\partial F_{w}(r, t)}{\partial t}=\frac{1}{r} \frac{\partial}{\partial r}\left[D_{e}(r) \times r \frac{\partial C_{w s}}{\partial r}\right]
$$

Because the gel thickness, $\delta$, increase with time, this problem is a moving boundary problem. To facilitate the solution of the moving boundary problem, all equations are transformed to a stationary $z$-coordinate which is defined as

$$
z=\frac{(R-r)}{\delta}
$$

which means that $z=0$, at the wall (that is, $r=R$ ) and $z=1$, at the interface $(r=R-\delta)$. This transformation of Eq. 3 results in

$$
\begin{aligned}
\rho_{\mathrm{gcl}} \frac{\partial F_{w}(z, t)}{\partial t} & =z \frac{\dot{\delta}}{\delta} \rho_{\mathrm{gel}} \frac{\partial F_{w}(z, t)}{\partial z} \\
& +\frac{1}{\delta^{2}(R-\delta z)} \frac{\partial}{\partial z}\left[D_{e}(z)(R-\delta z) \frac{\partial C_{w s}}{\partial z}\right]
\end{aligned}
$$

The initial condition for the differential equation (Eq. 4) is given as

$$
F_{w}(z, 0)=\text { Initial wax content of the bulk oil mixture }
$$

For this case where the initial wax content of the bulk oil mixture is $3 \mathrm{wt}$. $\%$,

$$
F_{w}(z, 0)=0.03
$$




\section{Energy balance inside the deposit}

A one-dimensional steady-state energy balance on a differential element of the wax deposit (Figure 6), considering latent heat of crystallization, $\Delta H_{f}$, of the wax molecules in the deposit layer, can be written as

$$
\left.(A q)\right|_{r}-\left.(A q)\right|_{r+\Delta r}+A \Delta r \rho_{g e l} \frac{\partial F_{w}(r, t)}{\partial t} \Delta H_{f}=0
$$

The mass flux, $q$, by the concentration gradient can be written as

$$
q=-k_{e}(r) \frac{\partial T}{\partial r}
$$

and substituting Eq. 6 into Eq. 5, one obtains

$$
\frac{1}{r} \frac{\partial}{\partial r}\left[k_{e}(r) \times r \frac{\partial T}{\partial r}\right]=-\Delta H_{f} \rho_{\mathrm{gel}} \frac{\partial F_{w}(r, t)}{\partial t}
$$

In $z$-coordinates, the above equation transforms into

$$
\begin{aligned}
\frac{\partial}{\partial z}\left[k_{e}(z)(R-\delta z) \frac{\partial T}{\partial z}\right] & \\
& =-\Delta H_{f} \frac{\partial}{\partial z}\left[D_{e}(z)(R-\delta z) \frac{\partial C_{w s}}{\partial z}\right]
\end{aligned}
$$

Correlations for $k_{e}, D_{e}$, and heat- and mass-transfer coefficients are discussed in detail in the next sections.

\section{Boundary conditions}

At Pipe Wall. Temperature at the cold wall remains constant at all times (Figure 7). Hence,

$$
\left.T\right|_{r=R}=\left.T\right|_{z=0}=T_{a} \quad \text { for all time }
$$

There is no mass flux past the cold wall. Hence,

$$
\left.J\right|_{r=R}=\left.J\right|_{z=0}=0 \quad \text { for all time }
$$

At the Interface. Heat is transferred from the bulk oil to the wax deposit both by convection (Figure 7 ) and by material transport of the solidifying component. This rate of heat transfer can be written as

$$
\begin{aligned}
\left.q\right|_{r=R-\delta} & =\left.\left(-k_{e} \frac{d T}{d r}\right)\right|_{r=R-\delta}=h_{i}\left(T_{b}-T_{i}\right) \\
& +\Delta H_{f}\left[k_{l}\left(C_{w b}-C_{w i}\right)-\left.\left(-D_{e} \frac{d C_{w}}{d r}\right)\right|_{r=R-\delta}\right]
\end{aligned}
$$

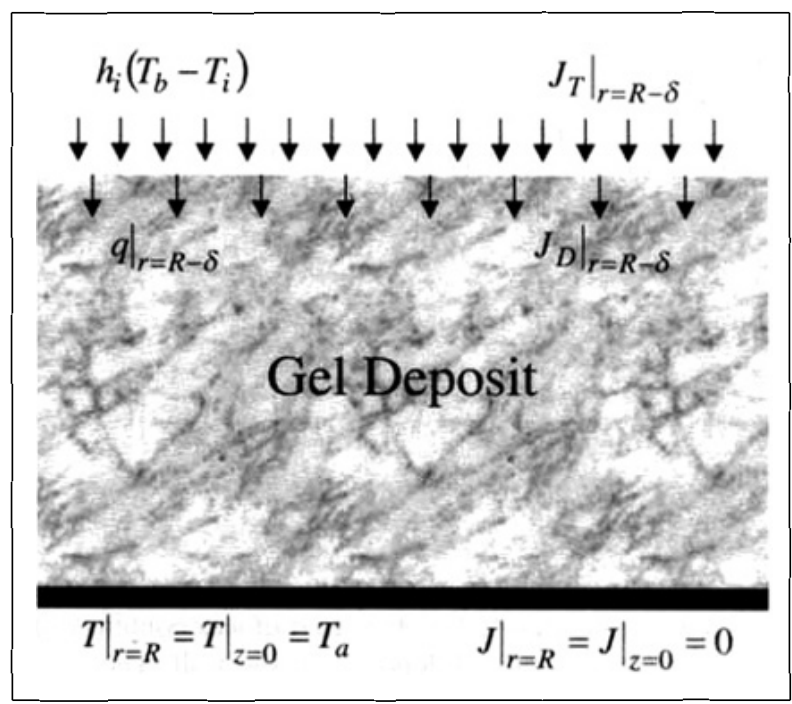

Figure 7. Gel deposit showing boundary conditions at the wall and at the gel-liquid interface.

and transformation into $z$-coordinate results in

$$
\begin{aligned}
\left.q\right|_{z=1}=\left.\left(\frac{k_{e}}{\delta} \frac{d T}{d z}\right)\right|_{z=1}=h_{i}\left(T_{b}-T_{i}\right) & +\Delta H_{f}\left[k_{l}\left(C_{w b}-C_{w i}\right)\right. \\
& \left.-\left.\left(\frac{D_{e}}{\delta} \frac{d C_{w}}{d z}\right)\right|_{z=1}\right]
\end{aligned}
$$

The total flux of wax that comes to the deposit interface (Figure 7) is given by

$$
\left.J_{T}\right|_{r=R-\delta}=k_{l}\left(C_{w b}-C_{w i}\right)
$$

Part of the mass diffuses in the interior of the wax deposit due to the concentration gradient exist at the interface. The rest of it increases the deposit thickness.

The diffusive mass flux into the wax deposit (Figure 7) can be written as

$$
\left.J_{D}\right|_{r=R-\delta}=\left.\left(-D_{e} \frac{d C_{w}}{d r}\right)\right|_{r=R-\delta}
$$

and the mass flux allocated to the growth of the deposit thickness can be written as

$$
\left.J_{G}\right|_{r=R-\delta}-F_{w}(R-\delta, t) \rho_{\mathrm{gel}} \frac{d \delta}{d t}
$$

The material boundary condition at the deposit interface can be written as

$$
\left.J_{T}\right|_{r=R-\delta}=\left.J_{D}\right|_{r=R-\delta}+\left.J_{G}\right|_{r=R-\delta}
$$


and can be reduced to (Eq. 2 in the article by Singh et al., 2000)

$$
F_{w}(R-\delta, t) \rho_{\mathrm{gcl}} \frac{d \delta}{d t}=k_{l}\left(C_{w b}-C_{w i}\right)-\left.\left(-D_{e} \frac{d C_{w}}{d r}\right)\right|_{r=R-\delta}
$$

and transformation into $z$-coordinate yields

$$
F_{w}(1, t) \rho_{\mathrm{gel}} \frac{d \delta}{d t}=k_{l}\left(C_{w h}-C_{w i}\right)-\left.\left(\frac{D_{e}}{\delta} \frac{d C_{w}}{d z}\right)\right|_{z=1}
$$

\section{Overall mass balance}

The wax concentration in the bulk oil, $C_{w b}$, continuously changes with time due to the depletion of wax content of the bulk oil as the wax-oil gel deposits on the wall. The overall mass balance is as follows.

Change in the wax content of the bulk oil = Total amount of wax deposit as gel

$$
V_{R}\left(C_{w b o}-C_{w b}\right)=\int_{0}^{L} \int_{R-\delta}^{R} 2 \pi r F_{w} \rho_{\mathrm{gel}} d r d L
$$

Rearrangement gives

$$
C_{w b}=C_{w b o}-\int_{0}^{L} \int_{R-\delta}^{R} \frac{2 \pi r F_{w} \rho_{\mathrm{gel}}}{V_{R}} d r d L
$$

Initial Condition. At time $t=0, y=0$ and $F_{w}=$ Initial wax content of the bulk oil mixture $=0.03$.

\section{Parameter values}

Correlations for the Transition Coefficients $h_{h}$ and $k_{l}$. For laminar flow in a pipe, the heat transfer coefficient can be obtained from the empirical correlations described below. The Hausen correlation (Hausen, 1943) is valid for long distances from the inlet and the Seider and Tate correlation (1936) is valid for short tubes. The actual correlations in the literature for a length-averaged value of the Nusselt number were converted to obtain the local value of the Nusselt number. The analogy between heat transfer and mass transfer was used to obtain the value of the mass transfer coefficient.

Hausen corrclation (1943)

$$
\begin{array}{r}
N u_{i}=3.66+1.7813 \times 10^{-3} \times\left[\frac{\left(G z_{i}\right)^{(5 / 3)}}{\left(1+0.04 \times\left(G z_{i}\right)^{(2 / 3)}\right)^{2}}\right] \\
\text { for } G z_{i}<100
\end{array}
$$

Seider and Tate correlation (1936)

$$
\begin{aligned}
N u_{i}=1.24 \times\left(G z_{i}\right)^{(1 / 3)}, \quad & \text { for } G z_{i}>100 \\
& \text { here } i=h \text { for heat transfer } \\
& \text { and } i=m \text { for mass transfer }
\end{aligned}
$$

Heat transfer coefficient, $h_{h}=\frac{N u_{h} \times k_{\mathrm{oil}}}{2 R}$

Mass transfer coefficient, $k_{l}=\frac{N u_{m} \times D_{w o}}{2 R}$

Thermal Conductivity of the Gel Deposit. The thermal conductivity of the gel deposit is assumed to be a function of its wax content. The following Maxwell correlation (Carslaw and Jaeger, 1959) was used to calculate the thermal conductivity of the gel

$$
k_{\mathrm{dep}}=\frac{\left[2 k_{\mathrm{wax}}+k_{\mathrm{oil}}+\left(k_{\mathrm{wax}}-k_{\mathrm{oil}}\right) \bar{F}_{w}\right]}{\left[2 k_{\mathrm{wax}}+k_{\mathrm{oil}}-2\left(k_{\mathrm{wax}}-k_{\mathrm{oil}}\right) \bar{F}_{w}\right]} k_{\mathrm{ojl}}
$$

Solubility of Wax in the Oil Solvent. The solubility of wax in the oil solvent, $C_{w s}$, is a strong function of temperature. The solubility decreases rapidly with decrease in the temperature of the solution. For a typical wax-oil, the solubility can be expressed as

$$
C_{w s}\left(T_{i}\right)=a\left(T_{i}+b\right)^{c}
$$

and the derivative of the solubility with temperature is given by

$$
\frac{d C_{w s}}{d T_{i}}=a c\left(T_{i}+b\right)^{c-1}
$$

where $T_{i}$ is in ${ }^{\circ} \mathrm{C}$. For the particular wax-oil mixture used in this, $a, b$, and $c$ are $1.31 \times 10^{-7} \mathrm{~kg} / \mathrm{m}^{3} \cdot \mathrm{K}^{5.1}, 17.8^{\circ} \mathrm{C}$, and 5.1 , respectively.

Effective Diffusivity of Wax Molecules into the Gel. The effective diffusivity of the wax molecules into the gel deposit is a function of porosity of the gel. It is assumed that the average aspect ratio ' $\alpha$ ' of the wax crystals is the ratio of length to thickness. Hence, the following equation (Cussler et al., 1988), derived for porous media of flake-like particles, is used for the effective diffusivity

$$
D_{e}=\frac{D_{w o}}{1+\alpha^{2} F_{w}^{2} /\left(1-F_{w}\right)}
$$

It is assumed that the aspect ratio of the wax crystals starts with 1 and is expected that as the wax content of the gel increases, the crystals will grow two-dimensionally to form a sheet. Hence, the aspect ratio is expected to increase with increasing wax content of the gel. It is assumed that the aspect ratio of the wax crystals varies linearly with the wax content of the gel deposit.

\section{Computational procedure}

The coupled partial differential equations (Eqs. 4 and 8) - the mass balance and energy balance equations developed for a differential element inside the gel deposit - were solved numerically using a finite difference scheme to obtain 
the temperature and wax content profiles inside the deposit as a function of time. The time trajectory of the thickness, $\delta$, was determined by numerically solving Eq. 15.

A closed system, wherein a fixed amount of oil recirculates through the pipe, was considered to simulate the laboratory flow loop. However, the bulk concentration of the wax would decrease with time as the wax-oil gel deposit grows. Here, the inlet temperature, $T_{b}$, is assumed to be a constant, by suitably using a reservoir maintained at that temperature.

Because the thickness and wax content of the deposit vary down the length of the pipe as well as with time, the integrations have to be performed with respect to both length and time. The length of the pipe was divided into 50 equal grids. This numerical scheme was tested for convergence and stability and found to be robust.

Solving the entire system of equations at a particular instant in time gives the profiles of the gel thickness and the wax content at that instant. With these profiles as initial values, the equations were again solved at the next time instant. This procedure was repeated up to $t=4$ days. Thus, the trajectories of thickness and wax content are obtained.

\section{Results and Discussions}

\section{Radial variation of wax content of thin deposits}

The thin-film model of wax deposition, which considered uniform properties of wax deposit in radial direction, accurately predicts the wax deposition of thin wax deposits. The comprehensive model for thick wax deposition was applied first to the limiting case of thin wax deposition. Figure 8 shows the radial profiles of the wax content in a thin wax deposit. The thickness of the deposit increases with time and approaches a value of $\delta=0.044 \times R=0.5 \mathrm{~mm}$ after 4 days. The wax content of the deposit also increases with time; however, the radial variation in the wax content is not more than $5 \%$ of its average value. In other words, the characteristic diffusion length of the wax molecules into the deposit is comparable to the thickness of the deposit and, thus, the entire deposit ages uniformly. The fact that the aging of the thin-film incipient wax deposit is uniform validates the assumption of a uniform wax content of the deposit in the thin-film model.

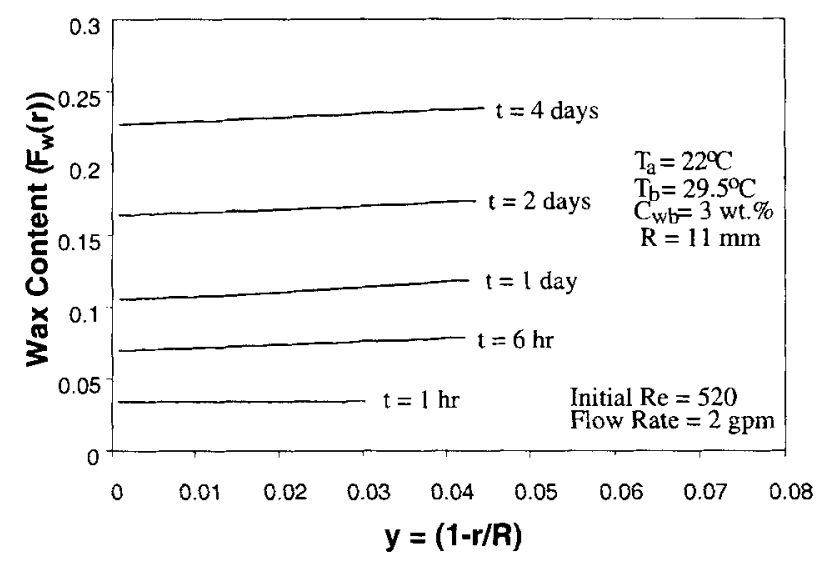

Figure 8. Simulation of radial variation of the wax content of a thin deposit with time.

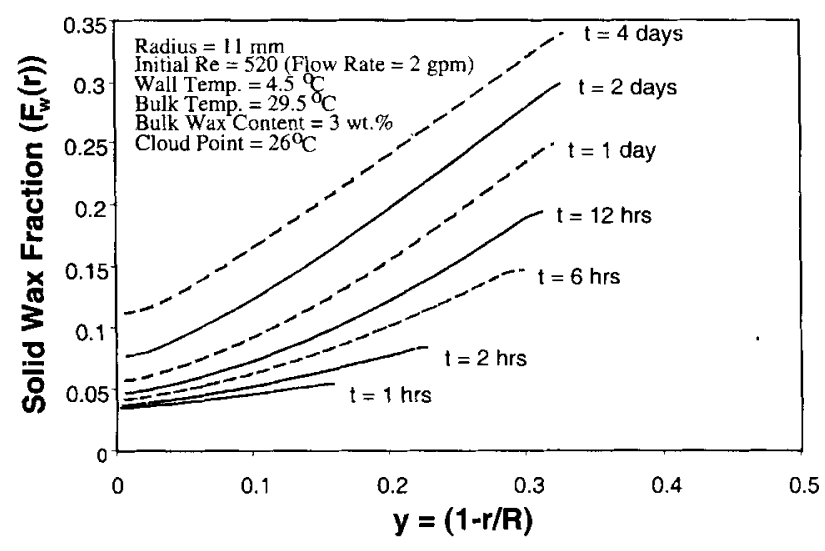

Figure 9. Radial variation of the wax content of a thick deposit with time.

\section{Radial variation of wax content of thick deposits}

Thick wax deposits in the flow loop were obtained by decreasing the wall temperature from $22^{\circ} \mathrm{C}$ to $4.5^{\circ} \mathrm{C}$. As seen in Figure 9 , the thickness of the deposit grows very fast for the first 6 hours and then stabilizes to an equilibrium value of $\delta=0.33 \times R=3.6 \mathrm{~mm}$. Hence, the thickness of the deposit for the conditions in Figure 9 was nearly seven times higher than that of the deposit for the condition in Figure 8. As was observed experimentally, the aging of the thick deposit was found to be radially nonuniform as shown in the comprehensive model simulation results in Figure 9. The deposit near the interface initially ages much more rapidly than that near the wall. As can be seen in Figure 9, the wax content of the deposit near the interface is significantly higher than that near the wall. In other words, because of thicker deposits, the characteristic diffusion length of the wax molecules into the wax deposit is shorter than the deposit thickness, hence the entire deposit does not age uniformly in the radial direction.

\section{Effect of operating conditions on the rate of deposition}

Flow Rate. To understand the effect of the flow rate on the deposition process, a series of gel deposition experiments were conducted in the laboratory flow loop at various flow rates in the laminar regime. An oil sample containing $3 \mathrm{wt} . \%$ wax at a temperature $29.5^{\circ} \mathrm{C}$ was flown through the flow loop at flow rates corresponding to Reynolds numbers of 260,520 and $1,040\left(1 \mathrm{gal} / \mathrm{min}\right.$ or $6.3 \times 10^{-5} \mathrm{~m}^{3} / \mathrm{s}, 2 \mathrm{gal} / \mathrm{min}$, and 4 $\mathrm{gal} / \mathrm{min}$, respectively). Table 1 shows the values of the parameters that were constant for all the experiments.

The wall of the tubing was kept constant at $4.5^{\circ} \mathrm{C}$, and the gel deposit thickness was monitored as a function of time.

Table 1. Parameters Fixed for All the Cases Studied

\begin{tabular}{lcc}
\hline \multicolumn{1}{c}{ Parameter } & Symbol & Value \\
\hline Length of pipe & $L$ & $8 \mathrm{ft}(2.44 \mathrm{~m})$ \\
Inner radius of pipe & $R$ & $1.1 \mathrm{~cm}$ \\
Vol. of reservoir & $V_{R}$ & $8 \mathrm{gal}\left(0.03 \mathrm{~m}^{3}\right)$ \\
Inlet temp. of oil & $T_{b}$ & $29.5^{\circ} \mathrm{C}$ \\
Initial wax content & $C_{w^{\prime} b}$ & $25.2 \mathrm{~kg} / \mathrm{m}^{3}$ \\
Run time & - & $4 \mathrm{~d}$ \\
\hline
\end{tabular}




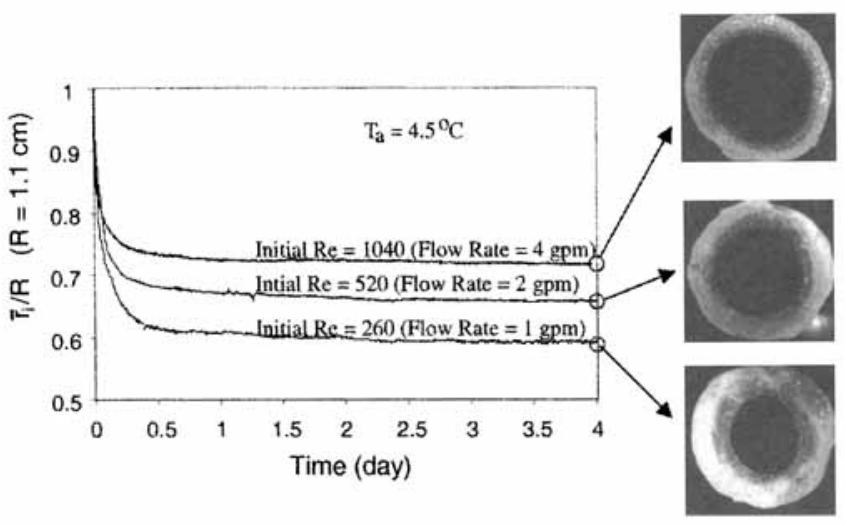

Figure 10. Average internal radius of the flowloop tubing as a function of time for various flow rates.

Figure 10 shows the average internal radius of the tubing as a function of time during wax deposition for the three different flow rates. In all three cases, the growth of the wax deposit virtually stops after a certain period of time. This condition arises as a result of the insulating effect of the wax deposit, that is, the thermal resistance of the wax deposit is sufficient to prevent further deposition in the flow loop. The deposit, however, may continue to grow in an actual subsea pipeline over long periods of time until the pipeline is essentially plugged, as shown in Figure 1. Figure 10 shows that the final thickness of the deposit decreases with an increasing flow rate. As the thickness of the gel deposit increases, the oil-gel interface temperature increases and approaches the cloud point temperature. Once the cloud point is reached, there is no further growth in thickness. At a higher oil flow rate, the rate of heat transfer is higher and, as a result, the interface temperature approaches the cloud point more rapidly and at a lower thickness of the deposit. Hence, as shown in Figure 10, the final deposit thickness is lower for a higher oil flow rate. Figure 10 also shows the deposits obtained from the flow loop at the end of 4 days.

Wall Temperature. The effect of the wall temperature on the growth of the wax deposit was also investigated using the flow loop. An oil sample containing $3 \mathrm{wt}$. \% wax at a temperature $29.5^{\circ} \mathrm{C}$ was passed through the flow loop with various wall temperatures $4.5^{\circ} \mathrm{C}, 9.5^{\circ} \mathrm{C}$, and $14.5^{\circ} \mathrm{C}$ and at a constant flow rate corresponding to a Reynolds number of 260 (1 $\mathrm{gal} / \mathrm{min}$ or $6.3 \times 10^{-5} \mathrm{~m}^{3} / \mathrm{s}$ ). Figure 11 shows the average internal radius of the tubing as a function of time during wax deposition for the three wall temperatures. Again, it is observed that in all three cases the growth rate of the wax deposit virtually stops after a period of time, due to the insulating effect of the gel deposit. The final thickness of the deposit is smaller for higher wall temperatures. A higher wall temperature results in a lower radial concentration gradient of the dissolved wax at thermodynamic equilibrium (keeping the bulk wax concentration fixed), which results in a lower driving force for the mass transfer. In addition, the gel-oil interface temperature reaches the cloud point at a smaller deposit thickness. These factors result in a reduced gel deposit thickness at a higher wall temperature. Figure 11 also

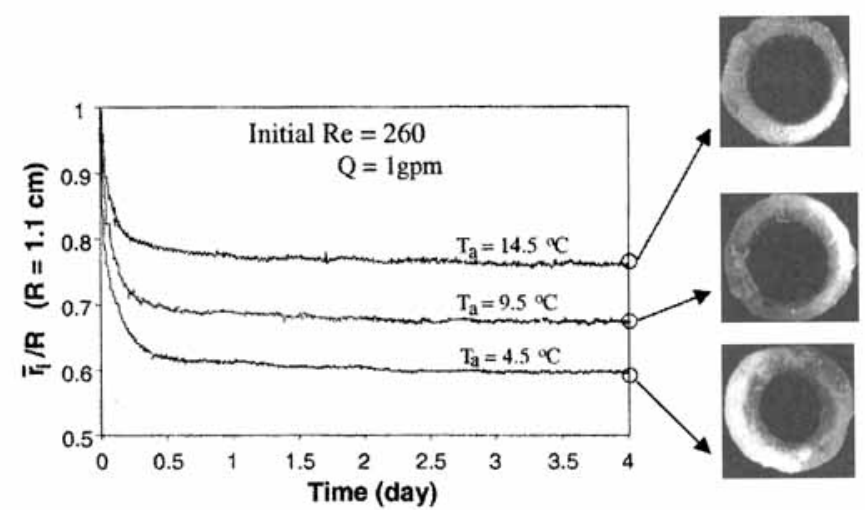

Figure 11. Average internal radius of the flowloop tubing as a function of time for various wall temperatures.

shows the deposits obtained from the flow loop at the end of 4 days.

\section{Effect of operating conditions on the composition of the deposit}

To study the effect of the operating conditions - the flow rate and the wall temperature-on the composition of the gel, the bisected layers of the gel deposits collected from the experiments described in the previous section were analyzed for their solid wax contents using differential scanning calorimetry. Figure 12 shows the solid wax content of the two layers of the gel deposits as a function of time for the three flow rates. The solid wax content of the layer near the interface is greater than that near the pipe wall. The wax contents of both of the layers are higher for higher flow rates. Figure 13 shows the wax content of the gel deposits as a function of time for the three wall temperatures. Again, the solid wax content of the layers nearest the interface is higher than that nearest the pipe wall. As seen from Figure 13, the wax content of the layers nearest the wall increases with increasing wall temperature, while the wax content of the layers nearest

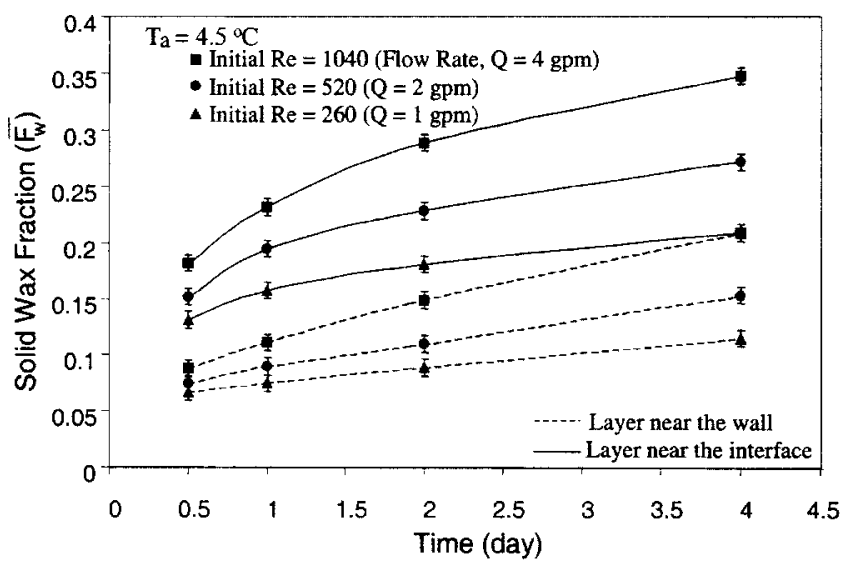

Figure 12. Wax content of the two layers of the gel deposit as a function of time for various flow rates. 


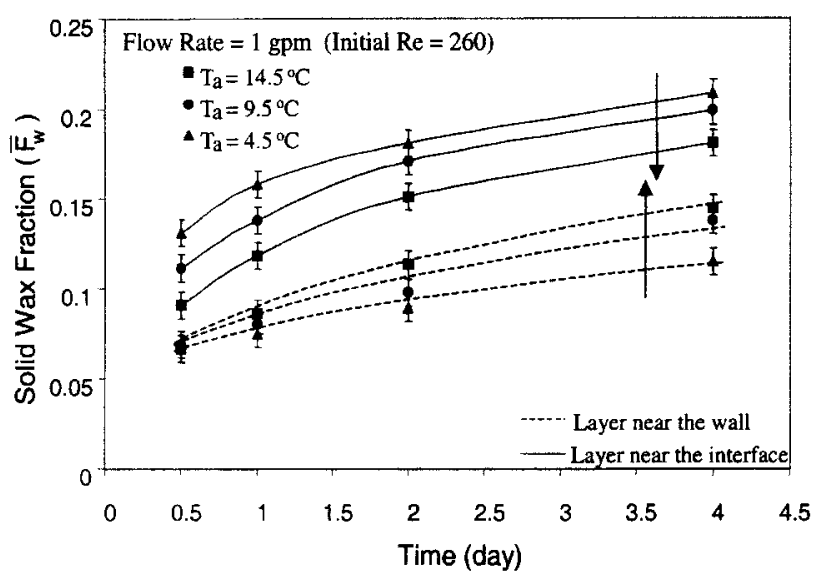

Figure 13. Wax content of the two layers of the gel deposit as a function of time for various wall temperatures.

the interface decreases with increasing wall temperature. As will be explained in later section, such a result is because the gel deposit thickness decreases with increasing wall temperature, and the system tends to behave more like the thin-film system.

\section{Comparison of Theory and Experiments}

Three different wall temperatures (at a fixed flow rate) and three different flow rates (at a fixed wall temperature) were studied, as specified in the previous section. In the discussion that follows, three trajectories of the experimental results must be mathematically described for a given experiment and set of conditions. Predictions of the mathematical model discussed previously were compared with the experimental data. One parameter, which is the aspect ratio of the wax crystals, is needed to be adjusted to describe all of the three trajectories. The data from the flow loop experiments and the corresponding theoretical predictions will be compared and discussed in the following section.

\section{Axial variation of gel thickness}

The gel deposit thickness is not uniform all along the length of the flow loop, because of the variation of the rates of heat and mass transfer along the length. The experimental results discussed previously showed the average thickness along the length of the flow loop (Figures 10 and 11) calculated from the total pressure drop across the entire test section. The simulation results provide the thickness profiles at various times, the thickness increases slightly along the length of the flow loop at large times (Figure 14).

\section{Variation of flow rate}

The wax deposition model was used to predict the results for the experimental conditions discussed in the previous section. Figure 15 shows the predicted radial composition profiles of the wax deposits at the end of 4 days for various flow rates at constant wall and bulk temperatures of $4.5^{\circ} \mathrm{C}$ and $29.5^{\circ} \mathrm{C}$, respectively. One observes that the thickness of the

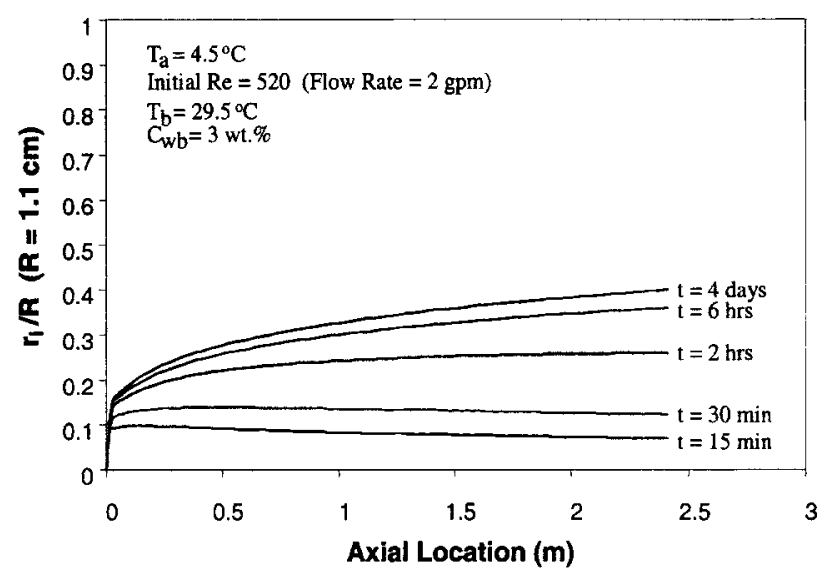

Figure 14. Simulation of thickness profiles along the length of the flowloop for various times.

deposit decreases with increasing flow rate while the solid wax fraction of the deposit increases with increasing flow rate. This observation is commensurate with the claim that a smaller deposit thickness results in a higher solid wax fraction of the deposit, given the same temperature difference across the deposit. This result may be attributed to the fact that, for a fixed temperature difference across the deposit, a smaller deposit thickness results in a larger temperature gradient across the deposit, leading to a higher diffusive flux of the wax inside the deposit and hence a higher solid wax fraction. The wax contents of the two layers of the deposit collected from the flow loop at these flow rates are also shown in Figure 15 along with the simulation results. One observes excellent agreement between the two.

Figures 16, 17 and 18 show comparisons of the experimental and theoretically predicted trajectories of the average internal radius and the wax content of the two layers of the deposit for the three different flow rates described previously (at a constant wall temperature). For the case of Figure 16, the average aspect ratio of the wax crystals was assumed to vary linearly with the wax content of the deposit, from a value of 1 to 6 . For the case of Figure 17, the aspect ratio varied

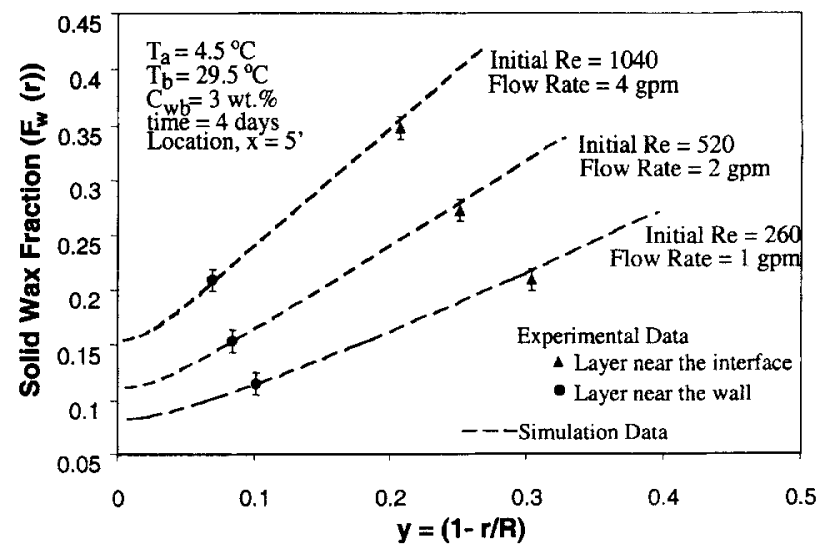

Figure 15. Radial composition profiles of the deposits for various flow rates and corresponding experimental data. 


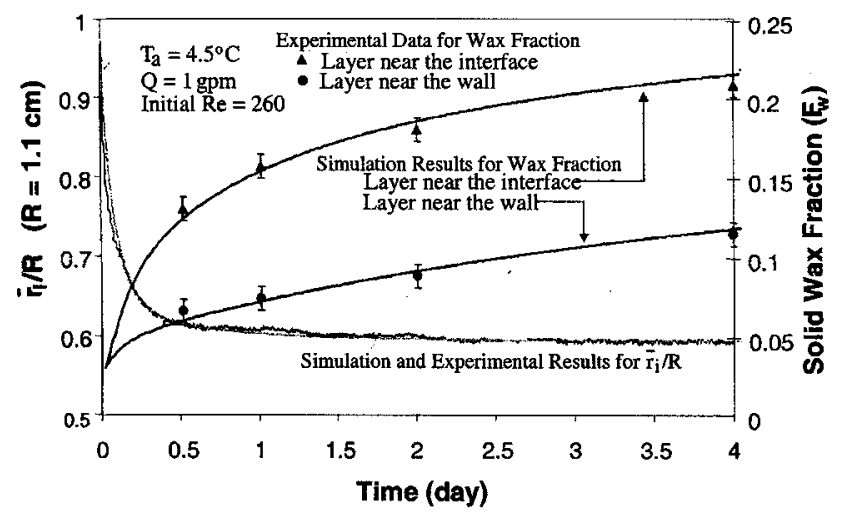

Figure 16. Comparison between theory and experiment for the wax deposition under a flow rate of 1 $\mathrm{gpm}$ and wall temperature of $4.5^{\circ} \mathrm{C}$.

from 1 to 4, whereas, for the case of Figure 18, it varied from 1 to 3 . There is excellent agreement between theory and experiment for all the three cases.

\section{Variation of wall temperature}

Figure 19 shows the radial composition profiles of the wax deposits (at an axial location of $x=5 \mathrm{ft}$ from the inlet) at the end of 4 days for three different wall temperatures and for the same flow rate and bulk temperature of $1 \mathrm{gal} / \mathrm{min}(0.0631$ $\mathrm{L} / \mathrm{s}$ ) and $29.5^{\circ} \mathrm{C}$, respectively. It can be observed that the thickness of the deposit decreases with increasing wall temperature.

Figures 16, 20 and 21 show the comparisons between theory and experiment for the three wall temperatures described previously, with the same flow rate of $1 \mathrm{gal} / \mathrm{min}$. For all these three cases, the aspect ratio had the same linear variation with the wax content of the deposit. Again, these figures, which describe two completely different but simultaneous measurements, show the excellent agreement between theoretical predictions and experimental data.

Figures 8 and 9 showed that the radial variation in wax content of a thick deposit is much greater than that of a thin

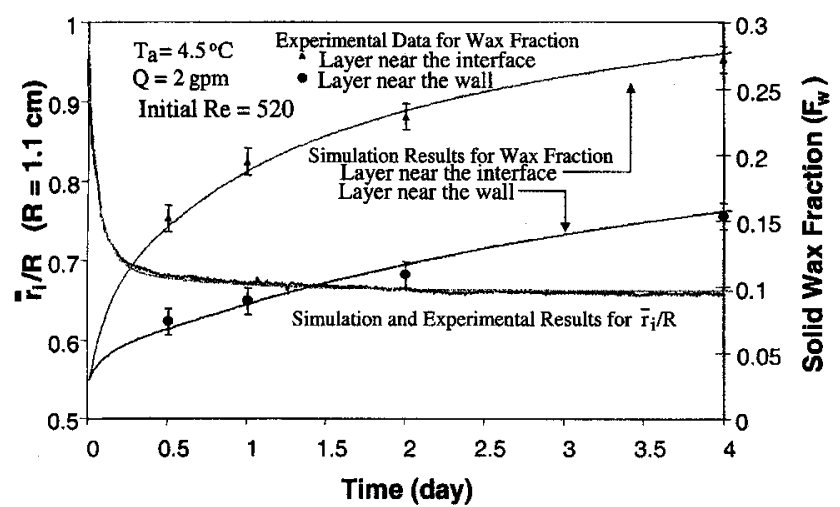

Figure 17. Comparison between theory and experiment for the wax deposition under a flow rate of 2 gpm and wall temperature of $4.5^{\circ} \mathrm{C}$.

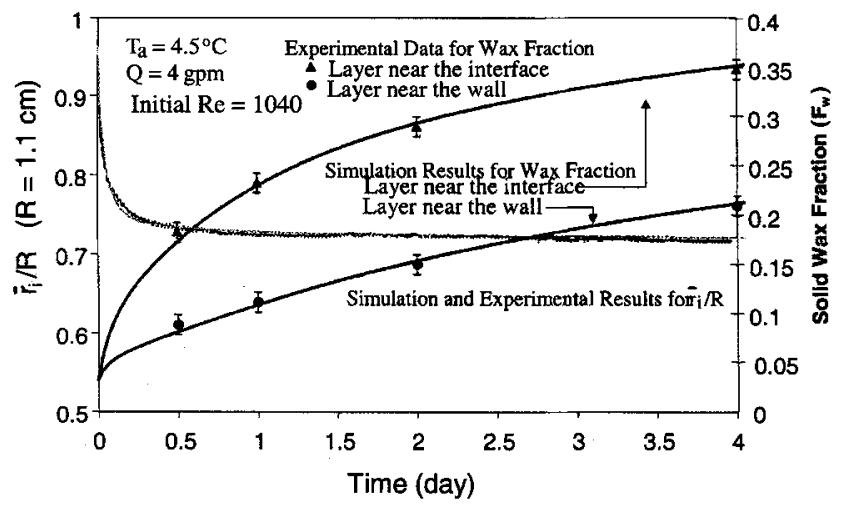

Figure 18. Comparison between theory and experiment for the wax deposition under a flow rate of 4 gpm and wall temperature of $4.5^{\circ} \mathrm{C}$.

deposit. Therefore, the degree of radial variation in the solid wax fraction of the deposit decreases as the thickness of the deposit decreases (with increasing wall temperature). In addition, Figure 13 showed the effect of the wall temperature on the wax content of the two layers. The decrease in the wax content of the interface layer and the increase in the wax content of the wall layer with increasing wall temperature also indicate that the degree of radial variation in the solid wax fraction of the deposit decreases with increasing wall temperature.

To clarify this point, mathematical simulations were carried out for wall temperatures for the conditions of the flow loop and extending wall temperatures above the experimental conditions. Figure 22 shows the wax contents of the two layers of deposit at time $t=4$ days as a function of the wall temperature along with the final deposit thickness. This figure shows that the difference between the wax contents of the two layers decreases with increasing wall temperature even as the thickness of the deposit decreases. As the deposit thickness decreases, the wax molecules can diffuse further into the deposit, thus making the aging process virtually uniform and the system tends to behave as a thin-film system.

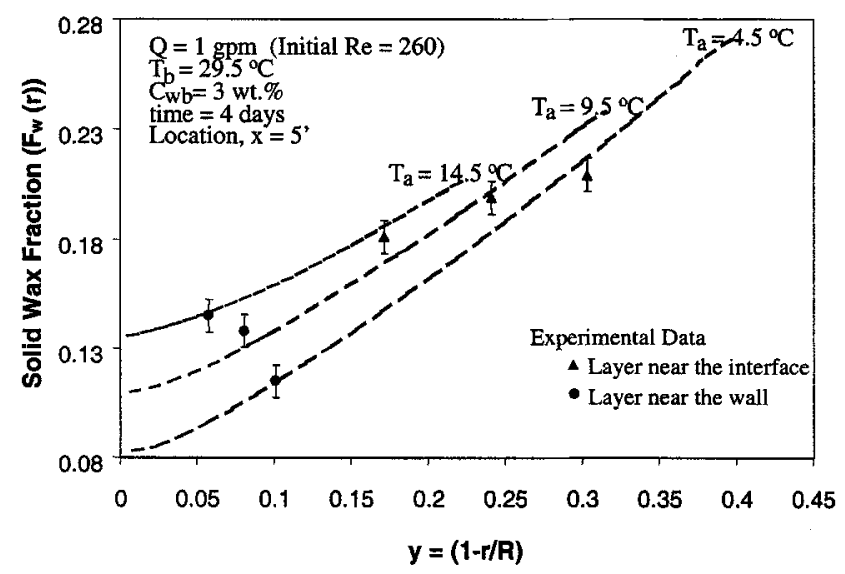

Figure 19. Radial composition profiles of the deposits for various wall temperatures. 


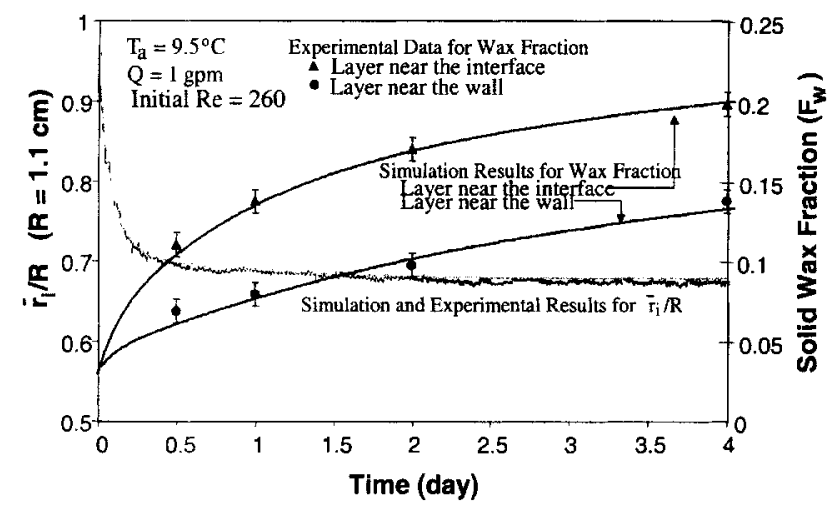

Figure 20. Comparison between theory and experiment for the wax deposition under a flow rate of 1 gpm and wall temperature of $9.5^{\circ} \mathrm{C}$.

Hence, the thin-film deposit model may be used for describing the results with the wall temperature above $20^{\circ} \mathrm{C}$; however, the thick deposit model is necessary if the accurate prediction of the wax deposition is desired for the wall temperatures below $20^{\circ} \mathrm{C}$ under these conditions.

\section{Conclusions}

In petroleum production, transportation and processing, deposition of organic material (such as paraffin wax) in the flow lines reduces the flow capacity of the flow line. The formation of the paraffin deposits, at the pipe walis, restricts the flow resulting in a large production loss and even plugging of pipelines creating great economic consequences. High molecular weight paraffins form stable crystals at low temperatures due to the low solubility of these compounds in aromatic or naphthenic solvents. This crystallization of paraffins leads to the formation of gels with a complex morphology. A model system of wax and oil was used to understand the gelation process of these mixtures. The incipient wax-oil gel deposited on the wall of the flow loop has a significant amount of oil trapped in the 3-D network structure of the wax crystals. As a result, the gel behaves as a porous medium into which wax molecules continue to diffuse resulting in an increase in the wax content of the deposited gel with time.

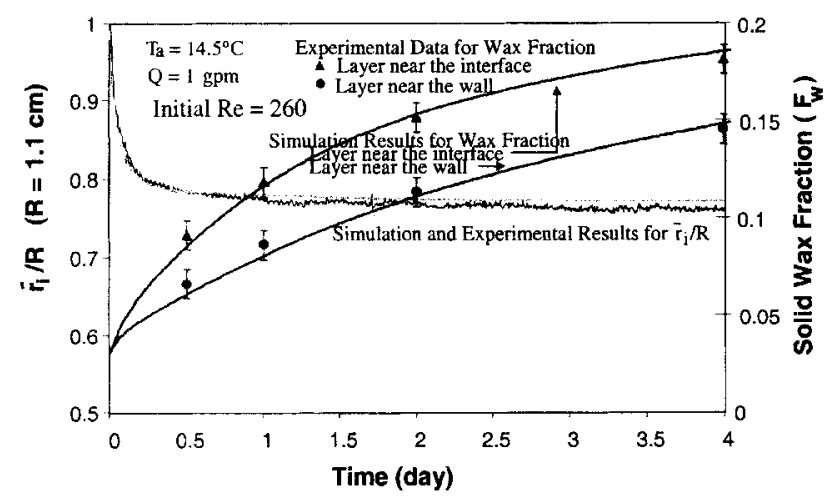

Figure 21. Comparison between theory and experiment for the wax deposition under a flow rate of 1 gpm and wall temperature of $14.5^{\circ} \mathrm{C}$.

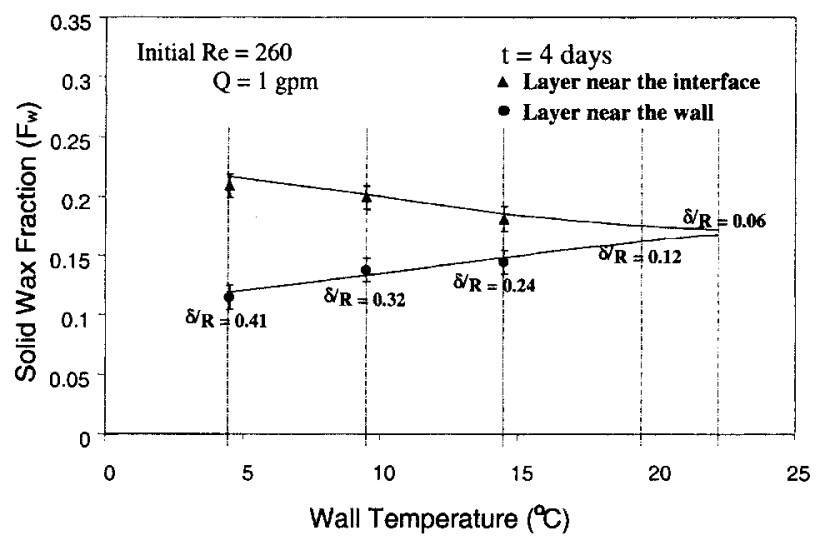

Figure 22. Composition of the deposit after four days as a function of the wall temperature.

A series of laboratory flow loop experiments were carried out for various lengths of time to elucidate the physics of the aging process of the gel deposit. The deposited gels collected from these experiments were analyzed and the wax content of the gel was found to be a strong function of the aging time as well as radial location. The deposit was collected from the spool piece in the flow loop and was divided into two layers. The layer near the liquid-gel interface was found to have higher wax content compared to the layer near the pipe wall. It was also observed that the aging of the gel deposit is a strong function of the temperature difference across the gel. A mathematical model was developed to describe the wax deposition process in a laboratory flow-loop apparatus. The system of coupled partial differential and algebraic equations generated from heat and mass balances inside and outside the gel deposit was solved numerically. An increase in the wall temperature results in a decrease in the gel thickness, an increase in the wax content of the wall layer and a decrease in the wax content of the interface layer. An increase in the flow rate increases the wax content of both layers. The mathematical model shows an excellent agreement with the experimental observations.

\section{Acknowledgments}

The authors wish to acknowledge Chris Koh and Taras Makogon for their help. The authors would also like to thank the laboratory staff at the Mobil Technology Co., Dallas, for their laboratory support. We also gratefully acknowledge the continuous support of our affiliate companies: Baker Petrolite, Chevron, Conoco, PDVSA-Intevep, Halliburton, Phillips Petroleum, and Schlumberger and NSF.

\section{Notation}

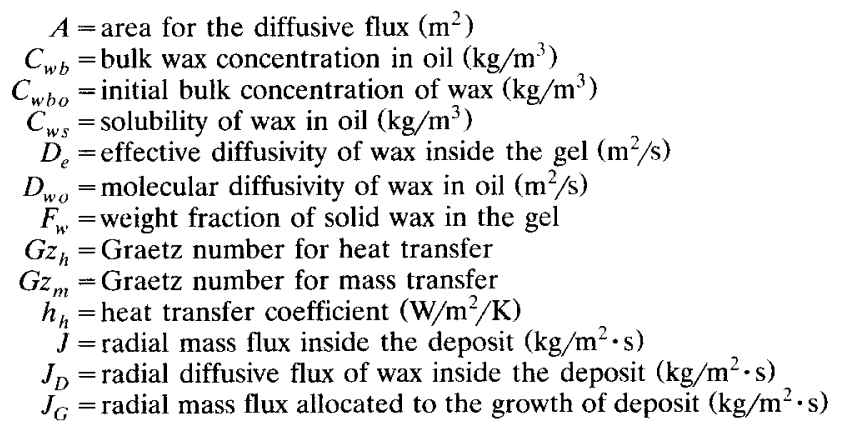


$J_{T}=$ total radial mass flux towards the deposit $\left(\mathrm{kg} / \mathrm{m}^{2} \cdot \mathrm{s}\right)$

$k_{e}=$ effective thermal conductivity of the $\mathrm{gel}(\mathrm{W} / \mathrm{m} / \mathrm{K})$

$k_{l}=$ mass transfer coefficient $(\mathrm{m} / \mathrm{s})$

$k_{\mathrm{oil}}=$ thermal conductivity of oil $(\mathrm{W} / \mathrm{m} / \mathrm{K})$

$k_{\text {wax }}=$ thermal conductivity of wax $(\mathrm{W} / \mathrm{m} / \mathrm{K})$

$L=$ length of the flow loop $(\mathrm{m})$

$N u=$ Nusselt number

$\operatorname{Pr}=$ Prandtl number

$q=$ radial heat flux inside the deposit $\left(\mathrm{W} / \mathrm{m}^{2}\right)$

$Q=$ flow rate $\left(\mathrm{m}^{3} / \mathrm{s}\right)$

$r=$ radial coordinate, $m$

$R=$ radius of the flow loop (m)

$R e=$ Reynolds number

$T=$ temperature inside the deposit

$T_{a}=$ ambient (wall) temperature $\left({ }^{\circ} \mathrm{C}\right.$ )

$T_{b}=$ bulk (oil) temperature $\left({ }^{\circ} \mathrm{C}\right.$ )

$T_{i}=$ interfacial temperature $\left({ }^{\circ} \mathrm{C}\right)$

$V_{R}=$ total volume in the closed system $\left(\mathrm{m}^{3}\right)$

$y=$ dimensionless thickness

\section{Greek letters}

$\Delta H_{f}=$ heat of solidification of wax $(\mathrm{J} / \mathrm{kg})$

$\rho_{\text {gel }}=$ density of the wax-oil gel $\left(\mathrm{kg} / \mathrm{m}^{3}\right)$

$\mu=$ viscosity of oil $(\mathrm{Pa} \cdot \mathrm{s})$

\section{Literature Cited}

Bern, P. A., V. R. Withers, and J. R. Cairns, "Wax Deposition in Crude Oil Pipelines," Proc. Euro. Offshore Petrol. Conf. and Exhibit., London, p. 571 (1980).

Bott, T. R., "Aspects of Crystallization Fouling," Exp. Thermal and Fluid Sci., 14, p. 356 (1997).

Brown, T. S., V. G. Niesen, and D. D. Erickson, "Measurement and Prediction of the Kinetics of Paraffin Deposition," Proc. SPE Technical Conf. and Exhibit., Houston, p. 353 (1993).

Burger, E. D., T. K. Perkins, and J. H. Striegler, "Studies of Wax Deposition in the Trans Alaska Pipeline," J. Pet. Tech., 33, 1075 (1981).

Carslaw, H. S., and J. C. Jaeger, Conduction of Heat in Solids, Oxford at the Clarendon Press, 2nd ed. (1959).

Clavell-Grunbaum, D., H. L. Strauss, and R. G. Snyder, "Structure of Model Waxes: Conformational Disorder and Chain Packing in Crystalline Multicomponent $n$-Alkane Solid Solutions," J. Phys. Chem., 101, 335 (1997).

Cussler, E. L., S. E. Hughes, W. J. Ward, and R. Aris, "Barrier Membranes," J. Memb. Sci., 38, 161 (1988).

Dirand, M., V. Chevallier, E. Provost, M. Bouroukba, and D. Petitjean, "Multicomponent Paraffin Waxes and Petroleum Solid Deposits: Structural and Thermodynamic State," Fuel, 77, 1253 (1998).

Dorset, D. L., and R. G. Snyder, "Crystal Structure of Modulated n-Paraffin Binary Solids," J. Phys. Chem., 100, 9848 (1996).

Dorset, D. L., "Structural Interactions between $n$-Paraffins and Their Perdeuterated Analogues: Binary Compositions with Identical Chain Lengths," Macromol., 24, 6521 (1991).

El-Hattab, M. I., "Scale Deposition in Surface and Subsurface Production Equipment in the Gulf of Suez," J. Pet. Tech., 37, 1640 (1985).

Hamouda, A. A., and S. Davidsen, "An Approach for Simulation of Paraffin Deposition in Pipelines as a Function of Flow Character- istics with Reference to a Tesside Oil Pipeline," Proc. SPE Int. Symp. on Oilfield Chemistry, San Antonio, p. 213 (1995).

Hamouda, A. A., and B. K. Viken, "Wax Deposition Mechanism Under High Pressure and in Presence of Light Hydrocarbons," SPE 25189 (1993).

Hausen, H., "Darstellung des Wärmeuberganges in Rohren durch verallgemeinerte Potenzbeziehungen," VDIZ, 4, 91 (1943).

Hayduk, W., and B. S. Minhas, "Correlations for Prediction of Molecular Diffusivities in Liquids," Can. J. Chem. Eng., 60, 295 (1982).

Holder, G. A., and J. Winkler, "Wax Crystallization from Distillate Fuels: I. Cloud and Pour Phenomena Exhibited by Solutions of Binary n-Paraffin Mixtures," J. Inst. Petrol., 51, 228 (1965).

Holder, G. A., and J. Winkler, "Wax Crystallization from Distillate Fuels: II. Mechanism of Pour Depression," J. of Inst. Petrol., 51, 235 (1965).

Hunt, E. B., "Laboratory Study of Paraffin Deposition," J. Pet. Tech., $1259(1962)$

Lee, K. S., W. S. Kim, and T. H. Lee, "A One-Dimensional Model for Frost Formation on a Cold Flat Surface," J. Heat Mass Transfer, 40, 4359 (1997).

Létoffé, J. M., P. Claudy, M. V. Kok, M. Garcin, and J. L. Volle, "Crude Oils: Characterization of Waxes Precipitated on Cooling by D.S.C. and Thermomicroscopy," Fuel, 74, 810 (1995).

Majeed, A., B. Bringedal, and S. Overa, "Model Calculates Wax Deposition for N. Sea Oils," Oil Gas J., 88, 63 (1990).

Neto, F. R. A., J. N. Cardoso, and A. S. Pereira, "Application of High Temperature High Resolution Gas Chromatography to Paraffin Deposits in Petroleum Production Pipelines," J. High Res. Chrom., 17, 259 (1994).

Pierre, A. C., K. Ma, and C. Barker, "Structure of Kaolinite Flocs Formed in an Aqueous Medium,"J. Mat. Sci., 30, 2176 (1995).

Riberio, F. S., P. R. S. Mendes, and S. L. Braga, "Obstruction of Pipelines due to Paraffin Deposition During the Flow of the Crude Oil," Int. J. Heat Mass Transfer, 40, 4319 (1997).

Seider, E. N., and C. E. Tate, "Heat Transfer and Pressure Drop of Liquids in Tubes," Ind. Eng. Chem., 28, 1429 (1936).

Singh, P, and H. S. Fogler, "Fused Chemical Reactions: The Use of Dispersion to Delay Reaction Time in Tubular Reactors," Ind. Eng. Chem. Res., 37, 2203 (1998).

Singh, P., H. S. Fogler, and N. Nagarajan, "Prediction of the Wax Content of the Incipient Wax-Oil Gel in a Flowloop: An Application of the Controlled-Stress Rheometer,'J. Rheol., 43, 1437 (1999).

Singh, P., R. Venkatesan, H. S. Fogler, and N. Nagarajan, "Formation and Aging of Incipient Thin Film Wax-Oil Gels," AIChE J., 46, 1059 (2000).

Srivastava, S. P., J. Handoo, K. M. Agrawal, and G. C. Joshi, "Phase-Transition Studies in $n$-Alkanes and Petroleum Related Waxes: A Review," J. Phys. Chem. Solids, 54, 639 (1993).

Svendsen, J. A., "Mathematical Modeling of Wax Deposition in Oil Pipeline Systems," AIChE J., 39, 1377 (1993).

Tao, Y. X., R. W. Besant, and K. S. Rezkallah, "A Mathematical Model for Predicting the Densification and Growth of Frost on a Flat Plate," Int. J. Heat Mass Transfer, 36, 353 (1993).

Wardhaugh, L. T., and D. V. Boger, "The Measurement and Description of the Yielding Behavior of Waxy Crude Oil," J. Rheol, 35, 1121 (1991).

Manuscript received May 30, 2000, and revision received Aug. 23, 2000. 